\title{
Chemical Characterization of Historical Brickwork of the Church Conventoin Pagsanjan, Laguna
}

\author{
Jan-Michael C. Cayme ${ }^{1 *}$, Aniano N. Asor ${ }^{1}$, Jr$_{\text {, }}$ Maveen Kim Alexis T. Alano ${ }^{2}$ \\ and Eric T. Miranda ${ }^{2}$ \\ ${ }^{1}$ Chemistry Department, College of Science, De La Salle University, 2401 Taft Avenue, Malate, Manila \\ ${ }^{2}$ School of Chemical Engineering and Chemistry, Mapua Institute of Technology, Intramuros, Manila
}

\begin{abstract}
This study reports the chemical composition of historical brickworks from Franciscanbuilt church complexes in the Philippines. An old brick sample from the Spanish colonial period church convento at Pagsanjan, Laguna was characterized by atomic absorption spectroscopy (AAS), infrared spectroscopy (IR), thermogravimetric analysis (TGA), and scanning electron microscopy with energy-dispersive X-ray spectroscopy (SEM-EDX). Conventional hot plate aqua regia $\left(1: 3 \mathrm{HNO}_{3}: \mathrm{HCl}, \mathrm{v} / \mathrm{v}\right)$ digestion method was employed to extract iron, calcium, and magnesium from the brick sample. The combined AAS and EDX results yielded a percentage composition of iron ranging from 5.48 to $6.62 \%$, calcium ranging from 1.50 to $3.72 \%$, while magnesium ranges from 0.083 to $0.12 \%$, respectively. These amounts were compared to a similar AAS and EDX study made on a historical brick sample from Ilocos Norte. The presence of possible pores on the brick's microstructure was confirmed by SEM. Minerals consisting of hematite, kaolinite, illite, quartz, and calcite were present in the sample, as well as trace amounts of other minerals based on IR peak intensities. Upon heating to about $800^{\circ} \mathrm{C}$ using TGA, the loss of bound water from the sample's internal surface structure and the decomposition of brick minerals and carbonates are evident.
\end{abstract}

Keywords: clay brick; atomic absorption spectroscopy; infrared spectroscopy; scanning electron microscopy with energy-dispersive X-ray spectroscopy; thermogravimetric analysis; cultural heritage conservation

\section{INTRODUCTION}

The Franciscan Order of Friars Minor or OFM was the second religious order that arrived in the Philippines in 1578 during the early years of the Spanish conquest of the country. They were given the task of handling the spiritual administration of the whole province of Laguna where Pagsanjan is located (Alarcon, 1998). Part of this work is the construction of church complexes which served as the Order's base of operations in a particular area. The complex is generally composed of the main church structure, the bell tower, the convento or the parish priest's residence and the cemetery. Most of these Franciscan-built structures still exist and have retained the old building materials which date back to the Spanish colonial period. In general, the Franciscan architectural style is described as having a humble simplicity, subdued and modest, which reflects the ideals

\footnotetext{
*Author to whom correspondence should be addressed; email: jm_cayme@yahoo.com
} 
and teachings of their founder, St. Francis de Assisi (Klassen, 2010).

The Pagsanjan church complex, also known as the Parish of Our Lady of Guadalupe, was built in 1688 from light construction materials made of bamboo and nipa under the supervision of the Franciscan missionary, Fray Agustin de la Magdalena. It was later replaced with a bigger and more permanent church structure made of adobe in 1690. This adobe structure was burned during the British occupation of the Philippines from 1762 to 1764 and was subsequently rebuilt. From about 1850's to 1870 's, a major renovation was initiated by the Franciscan Fray Joaquin de Coria by building a belfry and adding a huge dome on the church structure. This renovated structure suffered heavy damages during an American aerial bombing of Laguna in World War 2. It was eventually reconstructed following its original pre-war architectural design and the structure remains up to this day (Zaide, 1975).

The Franciscan archival records on the church convento's construction history are very scarce. The convento is a two storey structure made of adobe stones and clay bricks. These are common construction materials in Spanish-era Laguna Province. The brick materials used for construction are presumed to be manufactured in the latter part of the 1800's during the major church renovation done by Fray de Coria. These were evident from prewar archival photos, brick layering style and technique, and the physical characteristics of bricks found on the outer walls (Figure 1).

The convento's plan is rectangular in shaped with a cloister enclosing an open space (Figure 2 ), which in the olden days functions as an inner courtyard or a garden (Alarcon, 1998). One side of the convento forms the walls of the church and the back portion is connected to a capilla (small chapel). From the convento, the church can be accessed through the ground floor. The Franciscans originally built the convento following a design adapted from traditional Philippine architecture which was characterized by open and airy spaces. The second floor houses the parish residence, a spacious main sala (receiving room), kitchen area and the comedor (dining room). Other places for clinics, classrooms, storage spaces (bodegas) and some pens for domesticated animals are found on the ground floor (Jose, 1992; Mata, 2005). At present, the convento has been adapted for more modern use, containing a mixture of old and new construction materials, with elements of its original structure still apparent.

This study describes the chemical composition of a brick sample used as construction material on the outer front wall of the Pagsanjan church convento. The result will serve as a baseline data of historical brick chemical composition that is very important in restoration works and in the production of replacement bricks compatible with the original material. Sampling of brick material was performed to ensure that very minimal amount of sample were taken from the collection site which is adequate to accomplish the various instrumental techniques described in this study. The Pagsanjan church and adjoining convento are not in the Philippine National Museum's registry of National Cultural Treasures and National Cultural Churches.

The three important minor elements (iron, calcium and magnesium) which determine the brick's overall strength and durability were quantified using atomic absorption spectroscopy (AAS) techniques. This was supported by the total elemental composition data obtained from the scanning electron microscopy with energy-dispersive $\mathrm{x}$-ray spectroscopy (SEM-EDX) technique. The general clay mineral composition was provided by infrared spectroscopy (IR) while the quality of the brick sample in terms of its manufacturing process was shown using thermogravimetric analysis (TGA) and scanning electron microscopy (SEM) techniques.

\section{EXPERIMENTAL}

Collection of brick sample. The historical brick sample was acquired in December 2012 from an irregular-shaped loose brick fragment 


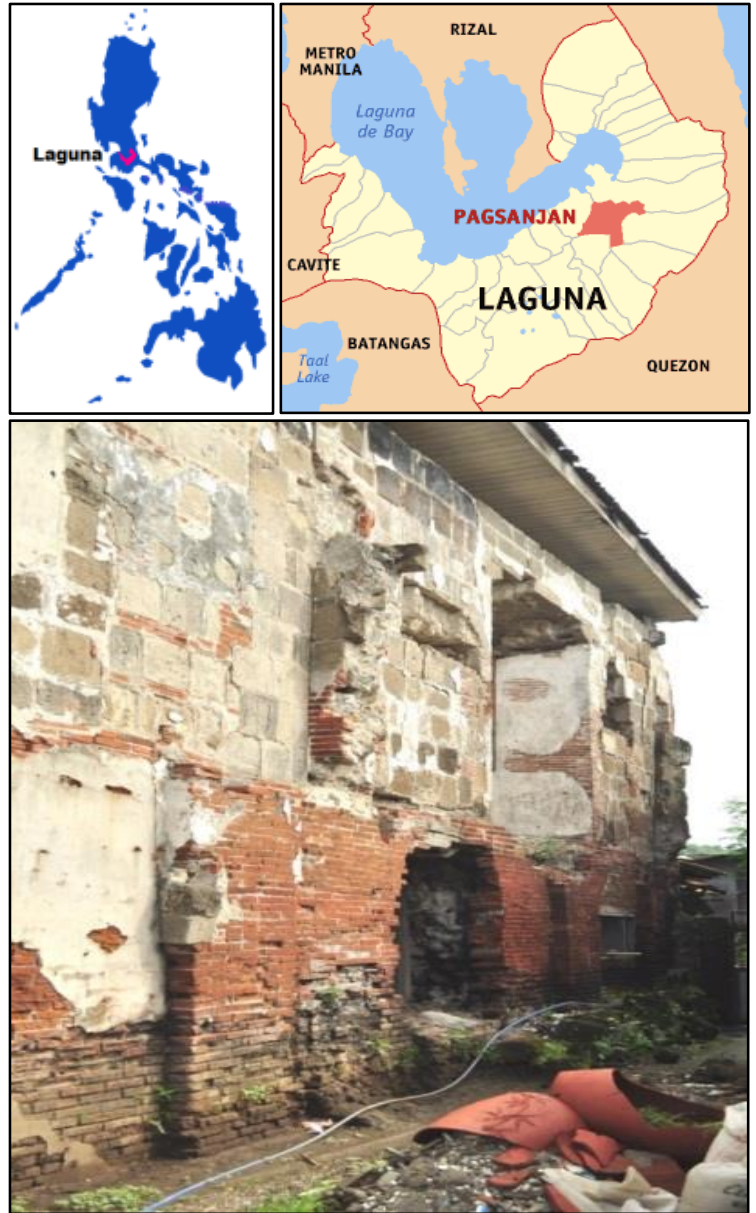

Figure 1: Location of Pagsanjan, Laguna and the old brick wall of the Pagsanjan church convento.

(about $5 \mathrm{~cm} \times 5 \mathrm{~cm} \times 4.5 \mathrm{~cm}$ ) approximately 3 feet from the base of the front wall portion of the church convento (Figure 2). The brick fragment has a light reddish-brown outer surface and light red interior. From this fragment, $12.4 \mathrm{~g}$ of brick sample was obtained at an approximate depth of $1-2 \mathrm{~cm}$ from the surface. The remaining brick fragment was returned afterwards.

Sample digestion for extracting iron and magnesium. Prior to digestion, three replicate powdered brick samples with a mass of about $0.5000 \mathrm{~g}$ each were soaked for 24 hours in $50 \mathrm{~mL}, 3: 1$ mixture of $\mathrm{HCl}$ and $\mathrm{HNO}_{3}$ (aqua regia) at room temperature. After this soaking period, each sample was further digested with another fresh mixture of $40 \mathrm{~mL}$ aqua regia solution for 3 hours on a hotplate at $110^{\circ} \mathrm{C}$. Upon evaporation to almost dryness, each replicate sample was diluted with $20 \mathrm{~mL}$ of $2 \% \mathrm{HNO}_{3}\left(\mathrm{v} / \mathrm{v}\right.$ with $\left.\mathrm{H}_{2} \mathrm{O}\right)$, centrifuged and
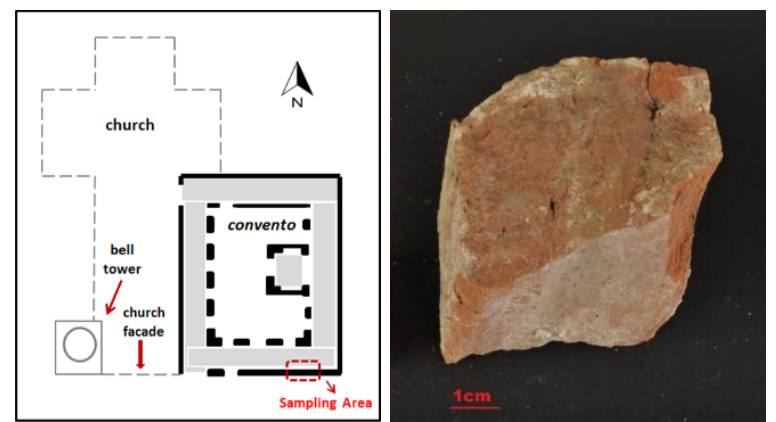

Figure 2: General floor plan of the Pagsanjan church complex and the sampling site. The brick fragment used in this study where a representative sample amount was obtained.

then decant. The supernatant liquid was diluted to the mark with distilled water in a $100 \mathrm{~mL}$ volumetric flask (Cayme and Asor, Jr., 2015).

\section{Sample digestion for extracting calcium.}

Conventional aqua regia digestion was performed on three sample replicates consisting of about $0.5000 \mathrm{~g}$ powdered brick sample in separate $250 \mathrm{~mL}$ glass beakers and covered with watch glass. Each sample replicate was digested separately for 3 hours on a hotplate in $40 \mathrm{~mL} 3: 1$ mixture of $\mathrm{HCl}$ and $\mathrm{HNO}_{3}$ (aqua regia) at $110^{\circ} \mathrm{C}$. Once the mixture evaporates to near dryness, each replicate was diluted with $20 \mathrm{~mL}$ of $2 \% \mathrm{HNO}_{3}$ (v/v with $\left.\mathrm{H}_{2} \mathrm{O}\right)$ and centrifuged. The supernatant was subsequently transferred into a $100 \mathrm{~mL}$ volumetric flask and diluted to the mark with distilled water (Cayme and Asor, Jr., 2015).

\section{Analysis by Atomic Absorption} Spectroscopy (AAS). A series of standard solutions were prepared from commercially available 1000 ppm iron, magnesium and calcium, AAS standard concentrates (Fluka brand, analytical standard grade) in separate 50 $\mathrm{mL}$ volumetric flasks and diluted to the mark with distilled water. A chemical suppressant, $2.5 \mathrm{~mL}$ of $5 \% \mathrm{w} / \mathrm{v} \mathrm{Sr}\left(\mathrm{NO}_{3}\right)_{2} \mathrm{was}$ added to each standard solution and brick sample for determining the calcium and magnesium contents. The calibration curves were prepared using the following concentration ranges: from $2 \mathrm{ppm}$ to $10 \mathrm{ppm}$ for iron, 0.3 $\mathrm{ppm}$ to $2 \mathrm{ppm}$ for magnesium and $0.1 \mathrm{ppm}$ to $2 \mathrm{ppm}$ for calcium. The blank solution used throughout the experiment was distilled water. The digested brick samples were prepared 
separately by diluting $2 \mathrm{~mL}$ aliquot for iron, 15 $\mathrm{mL}$ aliquot for magnesium, and $1 \mathrm{~mL}$ aliquot for calcium, respectively. Each sample aliquot was diluted to the mark with distilled water in individual $100 \mathrm{~mL}$ volumetric flasks. The absorbance was measured in a Shimadzu AA6300 Atomic Absorption Spectrophotometer with an air-acetylene gas mixture and hallowcathode lamps as radiation source. All measurements were done in triplicates. The wavelength for detection was adjusted to $248.3 \mathrm{~nm}$ for determining iron, $422.7 \mathrm{~nm}$ for calcium and $285.2 \mathrm{~nm}$ for magnesium, respectively.

\section{Analysis by Scanning Electron Microscopy with Energy-dispersive $\mathrm{X}$-ray Spectroscopy (SEM-EDX). SEM} observations in the back-scattered electron mode were recorded using the SEM/EDX JEOL JSM-5310 scanning microscope combined with Oxford Link Isis in the spotprofile mode, to characterize the microstructure of the brick material. The observations were performed by dispersing a small amount of dry, powdered brick sample on doubled sided conductive adhesive tape attached on an aluminium stub and coated with gold. The EDX elemental profile was also obtained from the SEM sample region taken at $62 \mathrm{eV}$ system resolution to determine the elemental composition.

Analysis by Infrared Spectroscopy (IR). The infrared spectrum was recorded using a Thermo Scientific Nicolet 6700 FT-IR Spectrophotometer in the mid frequency region (4000- $400 \mathrm{~cm}^{-1}$ ). A mixture of $\mathrm{KBr}$ powder and a small amount of powdered brick sample was grounded together and then pressed to form a transparent, thin pellet. The sample was initially heated in an oven for 3 hours at $105^{\circ} \mathrm{C}$ to ensure a completely dried sample.

Analysis by Thermogravimetric Analyzer (TGA). Thermal transformations of the brick sample were characterized using a Mettler Toledo TGA. A starting mass of $6.400 \mathrm{mg}$ brick sample was heated from a temperature range of 25 to $800^{\circ} \mathrm{C}$, under dynamic air and heating rate of $10^{\circ} \mathrm{C} /$ minute. The percentage by weight of the sample relative to the change in temperature was recorded.

\section{RESULTS AND DISCUSSION}

\section{Amount of Iron, Calcium and Magnesium} by Atomic Absorption Spectroscopy (AAS). Historical bricks or ladrillos are mainly made of clay mixed with sand and water. This mixture is then moulded, dried for days and locally fired in a borno or brick kiln (Navarro, 2007). The brick materials are usually sourced and manufactured in situ, thus, creating products that have different chemical compositions across every province in the Philippines (Fernandes et al, 2010).

Clays are composed of silicates and aluminates with varying amounts of metallic elements like iron, calcium and magnesium. These elements serve as fluxes which facilitate the fusion of mineral particles at lower temperature and influence the brick's overall quality and stability. The characteristic red color of bricks is also attributed to the amount of iron and the firing temperature (Torraca, 2009). Knowing the amount of these elements in a brick sample is crucial in manufacturing compatible materials for restoration works. The AAS data shows that among these three elements, the percentage of iron is higher in the sample with $5.870 \%$, followed by calcium with $3.328 \%$ and magnesium with $0.0893 \%$, respectively (Table 1 ). These quantities were computed based on the following calibration standard curve equations; for iron: $\mathrm{y}=0.041115 \mathrm{x}+0.028921 \quad(\mathrm{r}=0.9982)$, for calcium: $\quad \mathrm{y}=0.047340 \mathrm{x}+0.0012269$ $(\mathrm{r}=0.9995)$, and for magnesium: $\mathrm{y}=0.85056 \mathrm{x}$ $+0.41618(\mathrm{r}=0.9947)$. The results are within a 95\% confidence limit and the standard deviations signify that these values were clustered around the mean.

A similar AAS study was reported for a brick sample collected from Ilocos Norte (Cayme and Azor, Jr., 2015). It showed a percentage composition of iron in the range of 4.193 to $4.418 \%$, calcium from 0.123 to $0.203 \%$, and magnesium from 2.346 to $2.458 \%$, respectively. Figure 3 is a graph comparing the 
Table 1: Summary of AAS Data for Iron, Calcium and Magnesium Content.

\begin{tabular}{|c|c|c|c|c|}
\hline Element & Sample Code & $\begin{array}{c}\text { Mass of brick } \\
\text { sample (g) }\end{array}$ & $\begin{array}{c}\text { Average } \\
(\% \text { composition })\end{array}$ & $\begin{array}{c}\text { Mean } \\
\text { (Std. Deviation) } \\
\end{array}$ \\
\hline \multirow{3}{*}{$\mathrm{Fe}$} & $\mathrm{Fe}-01$ & 0.5062 & $6.379 \%$ & \multirow{3}{*}{$\begin{array}{c}5.870 \pm 1.14^{*} \\
(0.460)\end{array}$} \\
\hline & $\mathrm{Fe}-02$ & 0.5009 & $5.749 \%$ & \\
\hline & $\mathrm{Fe}-03$ & 0.5035 & $5.483 \%$ & \\
\hline \multirow{3}{*}{$\mathrm{Ca}$} & $\mathrm{Ca}-01$ & 0.5014 & $3.719 \%$ & \multirow{3}{*}{$\begin{array}{c}3.328 \pm 0.864^{*} \\
(0.348)\end{array}$} \\
\hline & $\mathrm{Ca}-02$ & 0.5030 & $3.052 \%$ & \\
\hline & $\mathrm{Ca}-03$ & 0.5009 & $3.212 \%$ & \\
\hline \multirow{3}{*}{$\mathrm{Mg}$} & $\mathrm{Mg}-01$ & 0.5062 & $0.094 \%$ & \multirow{3}{*}{$\begin{array}{c}0.089 \pm 0.0149 * \\
(0.006)\end{array}$} \\
\hline & $\mathrm{Mg}-02$ & 0.5009 & $0.083 \%$ & \\
\hline & $\mathrm{Mg}-03$ & 0.5035 & $0.091 \%$ & \\
\hline
\end{tabular}

$*$ at $95 \%$ confident interval

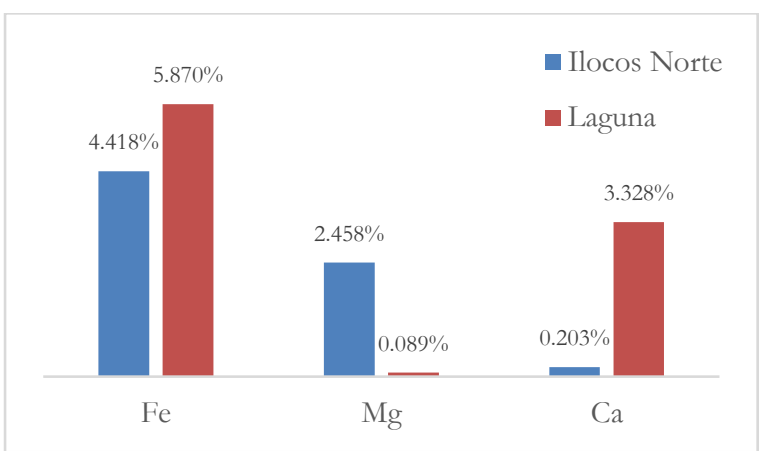

Figure 3: Comparison of the amount of iron, magnesium and calcium from Laguna and Ilocos Norte using $A A S$.

chemical components from these two different locations. The brick sample from Laguna was made with clay or inorganic raw materials rich in iron and calcium, while the sample from Ilocos Norte has higher magnesium content. These different values definitely influence the overall consistency of the brick products.

Total Elemental Composition using Energy-Dispersive X-Ray Spectroscopy (EDX). Table 2 shows that silicon, aluminium and iron are the major inorganic elements in the sample which is consistent with the clay and sand origin of historical bricks. A similar decreasing trend on the amount of iron $(6.62 \%)$ followed by calcium $(1.50 \%)$ and lastly by magnesium $(0.12 \%)$ was also observed in EDX (Table 2). Magnesium was present in trace amounts. These values show good agreement with the amount obtained from AAS. The difference between the percentage amounts of iron from AAS (5.870\%) with that of the EDX $(6.62 \%)$ is about $13 \%$, which is quite small. This indicates that iron is distributed homogeneously within the brick sample matrix. Moreover, the difference in the amount of calcium and magnesium between the two instrumental methods averages from greater than $50 \%$ for calcium, and about $20 \%$ for magnesium. Since these elements are lighter compared to iron and are more water soluble (Torraca, 2009), it is possible that its distribution from the brick sample may not be uniform.

A comparison of a similar EDX study made on a historic brick sample obtained from Ilocos Norte (Cayme, 2016) shows that there are variations in the chemical compositions depending on its location. This can be

Table 2: Elemental Percentage Composition of the Brick Sample from EDX

\begin{tabular}{cc}
\hline Element & Atomic $\%$ \\
\hline $\mathrm{O}$ & 43.65 \\
\hline $\mathrm{C}$ & 32.41 \\
\hline $\mathrm{Si}$ & 9.00 \\
\hline $\mathrm{Fe}$ & 6.62 \\
\hline $\mathrm{Al}$ & 5.91 \\
\hline $\mathrm{Ca}$ & 1.50 \\
\hline $\mathrm{Ti}$ & 0.44 \\
\hline $\mathrm{K}$ & 0.28 \\
\hline $\mathrm{Mn}$ & $0.07^{*}$ \\
\hline $\mathrm{Mg}$ & $0.12^{*}$ \\
\hline Total & $\mathbf{1 0 0 . 0 0}$
\end{tabular}

*trace amounts 
rationalized by looking at the geological features of these places. Pagsanjan Laguna is in close proximity with dormant volcanoes (Mt. Makiling and Mt. Banahaw), a volcanic complex (Maculod), and the Laguna de Bay, which is a volcanic-tectonic formation by caldera eruptions and extension tectonics. Most notable is the presence of collapse structure bounding Laguna de Bay that suggests a probable relic of a larger ancient caldera system (Adams, 1910). On the other hand, Ilocos Norte, which is on the western slope of the central Cordillera mountain range, is generally composed of shale, interbedded sandstone, and conglomerate with minor carbonate or tuffaceous components (Eslava-Faustino et al., 2013). These surrounding features greatly influence the elemental composition of the raw materials in making bricks.

The sample from Laguna has a higher percentage of iron compared to aluminates, while for the Ilocos Norte brick sample, aluminates are more abundant than iron (Figure 5). The greater percentage of iron $(6.62 \%)$ is attributed to ferromagnetic rocks which are abundant in the Laguna area compared to Ilocos Norte. Higher amounts of silicates $(9.00 \%)$ and oxygen (43.65\%) element from the Laguna sample are due to the presence of volcanic rocks which is common in the area and mainly in the form of $\mathrm{SiO}_{2}$. High percentage of silicon and oxygen elements confirms that silicic types of rocks are present as aggregates in the sample (Schumann, 1993). These volcanic rocks comprising the Macolod volcanic field have a wide range of composition from basalt to rhyolite type of minerals. Basalts occur only in small monogenetic centers in the Macolod Corridor, while dacites and rhyolites appears to be present only in the Laguna de Bay area and Mt. Makiling (Smith, 1913). These minerals are rich in $\mathrm{SiO}_{2}$ which is consistent with the EDX data.

For elements having percentage composition less than $2.00 \%$ (Figure 6 ), higher percentage of calcium $(1.50 \%)$ and potassium $(0.28 \%)$ obtained from the Laguna sample compared

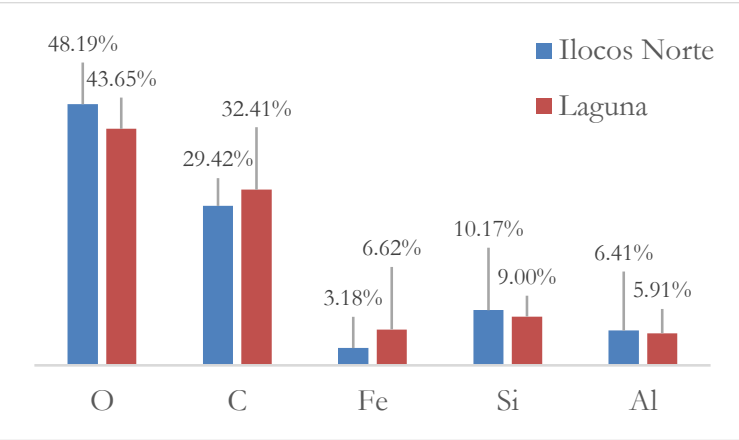

Figure 5: Comparison of the distribution of elements in the brick sample from Laguna and Ilocos Norte using EDX (for elements $>2.00 \%$ composition)

to the Ilocos Norte sample is typical of basalts type of minerals. These mineral types are mostly calc-alkaline, evolving to high potassium calc-alkaline for intermediate and evolved lavas. The Laguna de Bay lavas, in turn, are bimodally calc-alkaline and high potassium calc-alkaline (Soucek et al., 1989). The presence of magnesium $(0.12 \%)$ confirms the occurrence of ferromagnetic rocks in the surrounding area of Pagsanjan. Low amounts of the mineral rutile from rocks found in Laguna are evident from the element titanium $(0.44 \%)$. Trace amounts of manganese were attributed to subduction-related rocks which is also common in the Laguna area (Sudo et al., 2000). The soil from Laguna is not a good source of sodium and copper since the amount of these elements are very insignificant compared to the brick sample from Ilocos Norte. The occurrences of different elemental composition in two historic brick material supports the idea that different source of raw materials for brick making yields different properties. Hence a

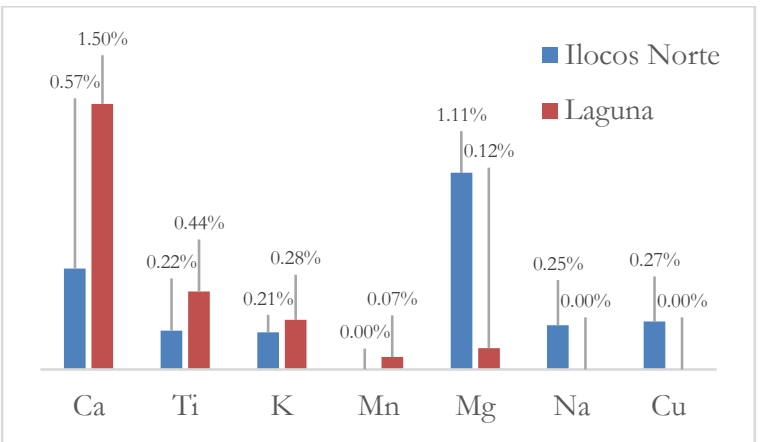

Figure 6: Comparison of the distribution of elements in the brick sample from Laguna and Ilocos Norte using EDX (for elements $<2.00 \%$ composition) 

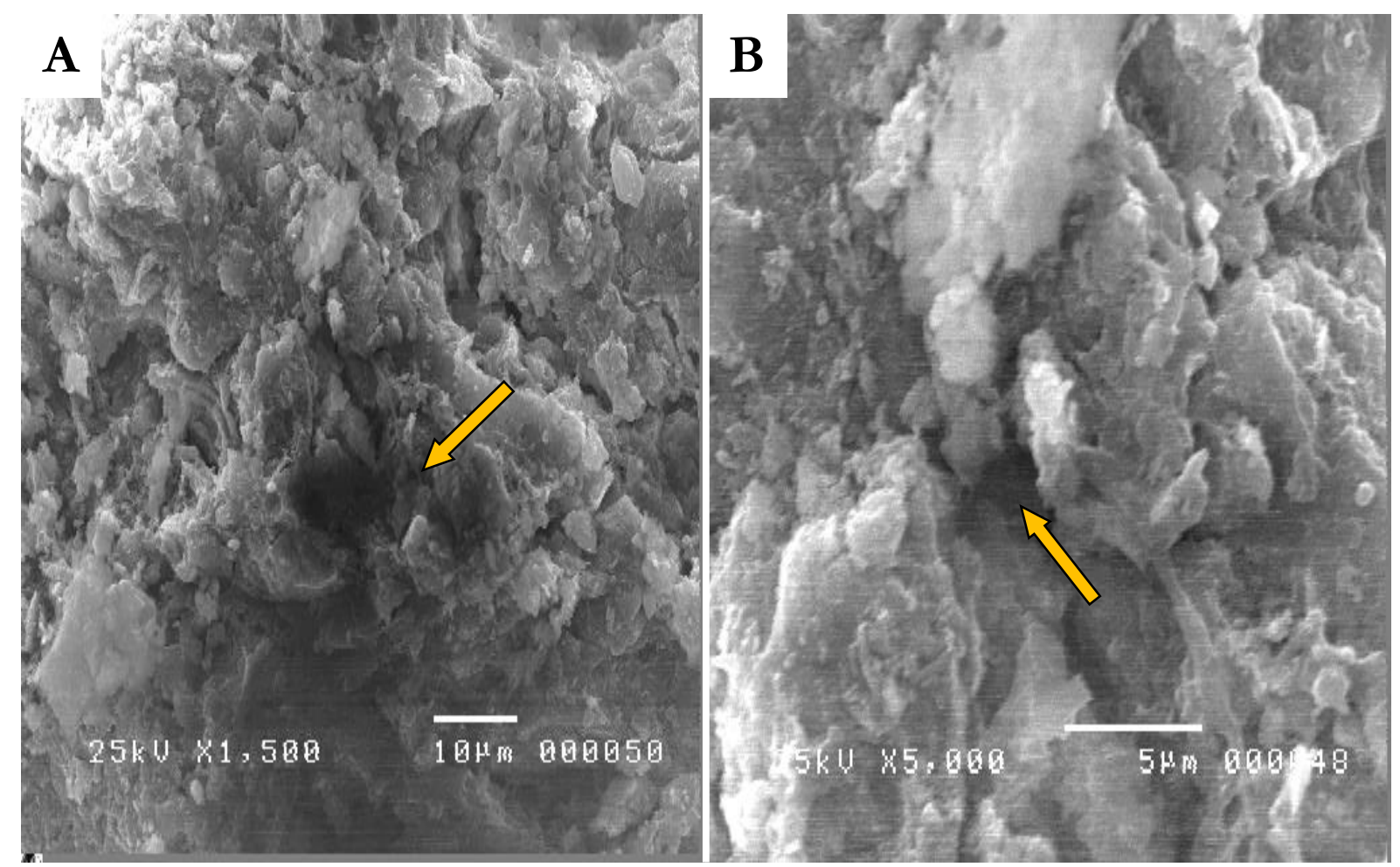

Figure 7: SEM image of the brick sample showing a magnification of (a) $\times 1,500$, and (b) $\times 5,000$. The arrow points to the possible pores on the bricks microstructure.

blanket approach of conserving historical bricks is not recommended. It is not unusual that Pagsanjan or Laguna province in general, may have manufactured their own bricks because it is a highly progressive town during the Spanish colonial period (Zaide, 1975).

\section{Brick Microstructure using Scanning} Electron Microscopy (SEM). The physical microstructure of the brick sample was analysed based on the SEM image on Figure 7. As shown in both magnifications (x1,500 and $\times 5,000)$, the presence of pores are evident. Different pore sizes of approximately $10 \mu \mathrm{m}$ (Figure 7A) and 2.5 $\mu \mathrm{m}$ (Figure 7B), respectively are observed, which might eventually lead to the weakening of the mechanical behaviour of the brick sample (Torraca, 2009). Evidence of weak regions in the brick microstructure is seen from the lack of crystal stacking in both SEM images.

\section{Mineralogical Composition using Infrared} Spectroscopy (IR). For an IR spectrum in general, the range from 3400 to $3750 \mathrm{~cm}^{-1}$ is assigned to $\mathrm{OH}$ stretching modes common in clay minerals; the absorbance from 700 to $1200 \mathrm{~cm}^{-1}$ is usually assigned to stretching modes for $\mathrm{Si}-\mathrm{O}$ and $\mathrm{Al}-\mathrm{O}$, and the metal-OH bending modes are seen from 600 to $950 \mathrm{~cm}^{-1}$ (Schroeder, 2002). Since the sample was heated at $105^{\circ} \mathrm{C}$ for 3 hours to drive out the water molecules prior to the IR analysis, the spectrum indicated a very weak band centered at $3475 \mathrm{~cm}^{-1}$ and $1618 \mathrm{~cm}^{-1}$ which are assigned to the remaining water molecules absorbed by the brick structure. Strong absorption bands were also observed for the fingerprint region from 400 to $1500 \mathrm{~cm}^{-1}$ which is important in inorganic mineral analysis (Derrick et al., 1999). This region was compared with major mineral constituents of clay and sand which are hematite, kaolinite, illite, quartz and calcite as shown in Figure 8. The IR spectrum for these mineral standards was obtained online from the Mineral Spectroscopy Server of the California Institute of Technology (Kelly, 2016). Their samples were done in $\mathrm{KBr}$ pellets, baseline corrected and analysed using Perkin Elmer FTIR Spectrometer.

Table 3 lists the absorption of these minerals in the IR fingerprint region compared with the brick sample and its assignments. It shows that the characteristic mineral peaks are also present in the brick sample confirming its clay 

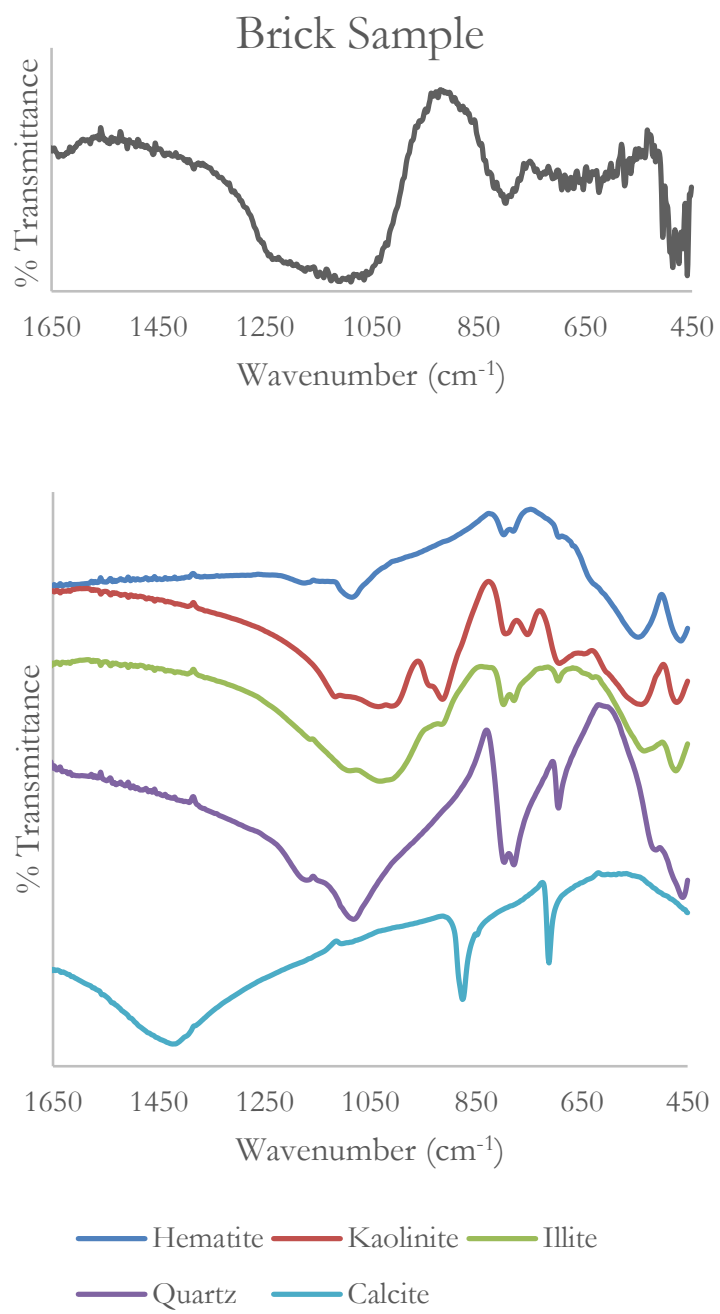

Figure 8: IR fingerprint region (450-1650 $\left.\mathrm{cm}^{-1}\right)$ of the brick sample together with reference spectra from common inorganic minerals found in clay and sand.

and sand origins. The fingerprint region of the brick sample has a broad peak approximately between $1000-1300 \mathrm{~cm}^{-1}$ (Figure 8) which is assigned to Si-O stretching (Petrenas et al., 2012). It is also present as broad peaks in the mineral kaolinite, illite and quartz. This is expected since these minerals contain silicon. Hematite, which is mainly composed of iron and oxygen, has a weak absorption band within this Si-O region $\left(1084 \mathrm{~cm}^{-1}\right)$. Like most mineral compounds, hematite is rarely found in pure composition (Schumann, 1993). Calcite which is mainly composed of $\mathrm{CaCO}_{3}$ doesn't absorb at this region. The sharp peak at $796 \mathrm{~cm}^{-1}$ on the brick sample is also assigned to a Si-O stretching (Petrenas et al., 2012). This is again present in the minerals kaolinite, illite and quartz. A weak band for this absorption was observed for the hematite and attributed to impurities in the natural sample. Quartz, which is mainly composed of $\mathrm{SiO}_{2}$ (Schumann, 1993), absorbed strongly at this wavenumber.

For pure calcite, which is mainly $\mathrm{CaCO}_{3}$, the important bands for $\mathrm{C}-\mathrm{O}$ are the out-of-plane bending (v2) at $874 \mathrm{~cm}^{-1}$, asymmetric stretching (v3) at $1420 \mathrm{~cm}^{-1}$ and the in-plane bending (v4) at $712 \mathrm{~cm}^{-1}$ (Sathya et al., 2012). Only the weak bands at $858 \mathrm{~cm}^{-1}$ (v2) and $769 \mathrm{~cm}^{-1}$ (v4) was observed from the brick sample (Figure 8).

The strong absorbance between 450-500 $\mathrm{cm}^{-1}$ in the brick sample is assigned to $\mathrm{Fe}-\mathrm{O}$ bending and Si-O-Si bending (Saikia et al., 2010). From Figure 8, hematite absorbs strongly at this region due to the presence of high concentrations of iron. The characteristic red color of bricks is attributed to this mineral. Illite also contains iron which explains its absorbance in this region. Kaolinite, illite and quartz absorbs strongly at this region due to the presence of silicon (Si$\mathrm{O}-\mathrm{Si}$ bending) in their crystal structure. Some absorption peaks in the brick sample was not fully resolved which signifies the presence of other mineral groups. This is expected since sand and clay are composed of different minerals.

\section{Thermal Analysis of Brick Sample using Thermogravimetric Analyser (TGA):} Figure 9 shows that around $750^{\circ} \mathrm{C}$, a visible decomposition of minerals in the brick sample was observed. Initially, there is partial oxidation of the sample in the ambient air at around $70^{\circ} \mathrm{C}$ which resulted to a slight increase in weight. As the temperature increase from 80 to $100^{\circ} \mathrm{C}$, the weight lost is attributed to the evaporation of water. It was followed by a constant loss of weight between 100 to $740^{\circ} \mathrm{C}$ which might be due to the combustion of organic matter and the further removal of trapped water inside the brick microstructure (Cardiano et al., 2004). The decomposition process culminates by a drop in weight detected between 750 to $800^{\circ} \mathrm{C}$ (Figure 10) which is due to the 
Table 3: Comparison of IR Peaks for the Major Mineral Components of Brick Raw Materials with the Sample.

\begin{tabular}{|c|c|c|c|c|c|c|}
\hline \multicolumn{6}{|c|}{ Wavenumber $\left(\mathrm{cm}^{-1}\right)$} & \multirow{2}{*}{ Assignments } \\
\hline Quartz & Calcite & Hematite & Illite & Kaolinite & Brick Sample & \\
\hline 454 & --- & 464 & 470 & 464 & 459 & Si-O-Si bending \\
\hline 506 & --- & 544 & 532 & 530 & 495 & $\begin{array}{l}\text { Fe-O bending } \\
\text { for hematite; } \mathrm{Si}- \\
\text { O-Al stretching }\end{array}$ \\
\hline 692 & --- & --- & 694 & $636-684$ & 671 & $\begin{array}{l}\text { Si-O for quartz; } \\
\text { Si-O-Si bending }\end{array}$ \\
\hline 774 & 712 & 780 & 776 & 746 & 769 & $\begin{array}{c}\text { (v4) } \mathrm{C}-\mathrm{O} \text { in } \\
\text { plane bending } \\
\text { for calcite; Si-O } \\
\text { stretching }\end{array}$ \\
\hline 792 & --- & 798 & 798 & 792 & 796 & $\begin{array}{l}\text { Si-O stretching; } \\
\text { OH deformation } \\
\text { linked to } \mathrm{Al}, \mathrm{Mg}\end{array}$ \\
\hline--- & 874 & --- & --- & --- & 858 & $\begin{array}{l}\text { (v2) C-O out-of- } \\
\text { plane bending } \\
\text { for calcite }\end{array}$ \\
\hline--- & --- & --- & 910 & 908 & --- & $\begin{array}{c}\mathrm{OH} \text { deformation } \\
\text { linked to } \mathrm{Al}\end{array}$ \\
\hline 1078 & --- & 1084 & 1030 & $1002-1032$ & 1070 & Si-O stretching \\
\hline--- & --- & --- & --- & 1112 & 1128 & Si-O stretching \\
\hline --- & 1420 & --- & --- & --- & --- & $\begin{array}{l}\text { (v3) C-O } \\
\text { asymmetric } \\
\text { bending for } \\
\text { calcite }\end{array}$ \\
\hline
\end{tabular}

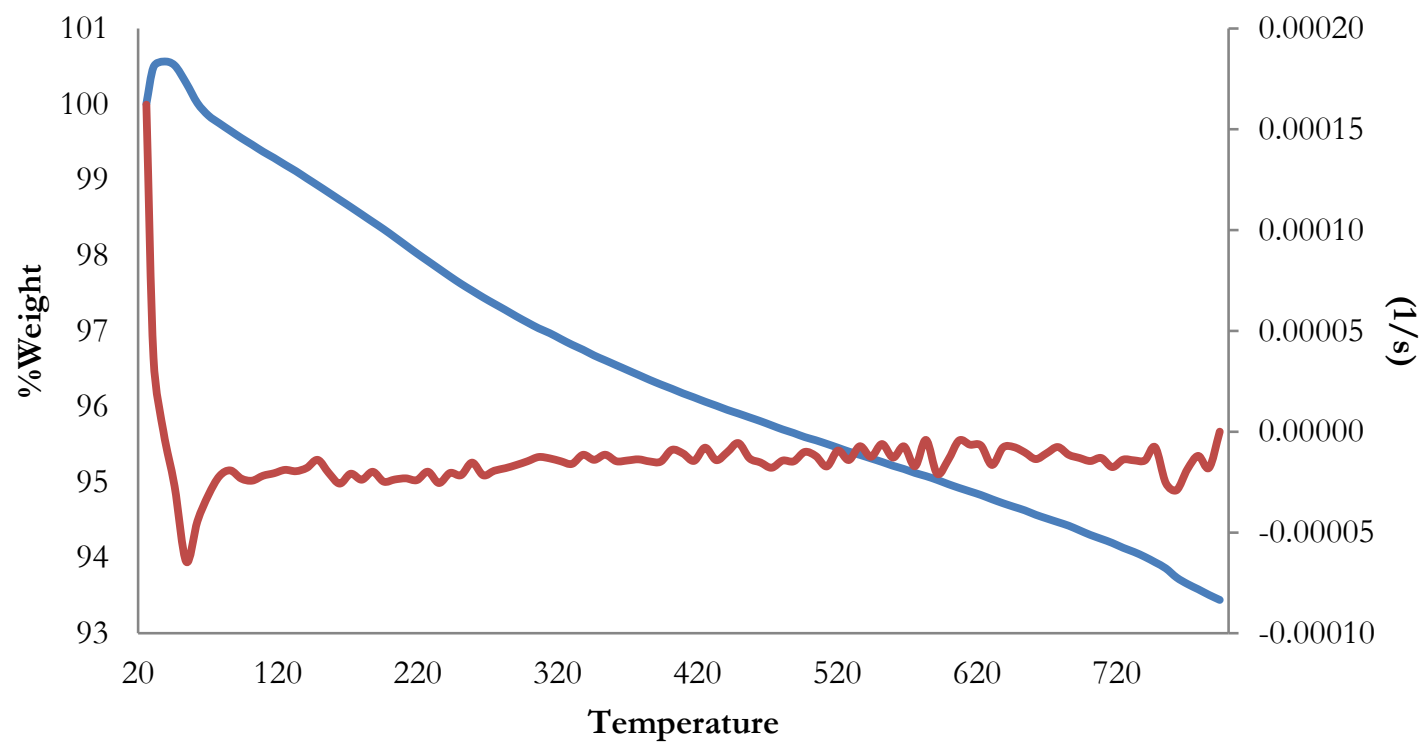

Weight $(\%) \quad$ First Derivative

Figure 9: Thermogravimetric analysis of the brick sample 


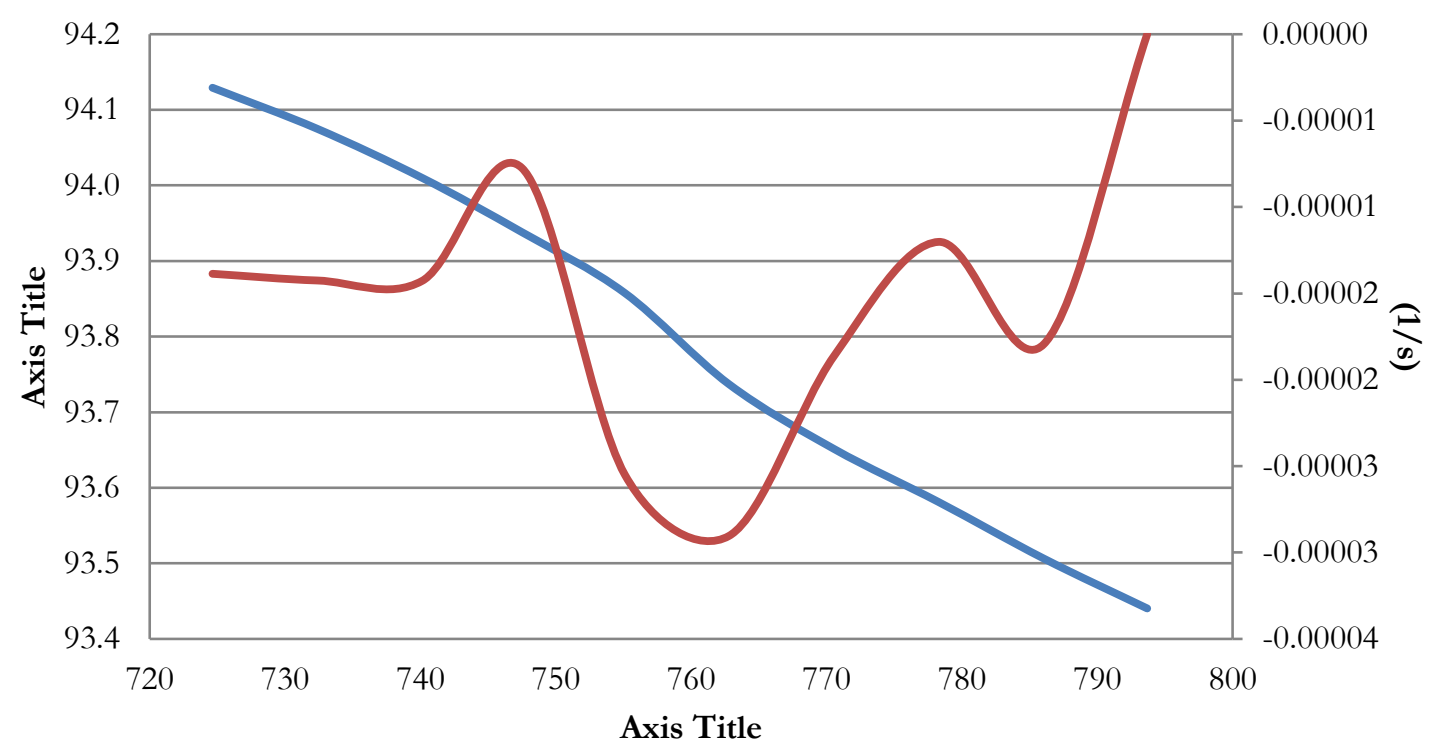

Weight $(\%) \quad$ First Derivative

Figure 10: Thermogravimetric analysis for temperature greater than $720^{\circ} \mathrm{C}$

dehydroxylation of illite and chlorites (Sutcu, 2014) as well as possible decomposition of calcite. Bricks are generally fired at a temperature ranging from 800 to $1,000^{\circ} \mathrm{C}$ in a borno (Navarro, 2007). Degradation was observed below this firing temperature which signifies the presence of non-ceramic materials which may be due to organic compounds in the brick sample.

\section{CONCLUSIONS}

This study is the first in a series of chemical characterizations of historical brick materials made under the guidance of the Franciscan friars. Further study is needed if there are unique brick making methods employed by the different religious orders in the Philippines. The importance of obtaining the brick raw materials for conservation work within the same vicinity of the old structure was highly emphasized. This will ensure that the brick product is more compatible in terms of its chemical and physical properties with the original material. Different distributions of iron, magnesium and calcium, which are important fluxing agents in manufacturing bricks, were observed upon comparison between the samples from the Pagsanjan church convento with another brick sample from an old church in Ilocos Norte. This difference was correlated with the geological characteristics of the two provinces and supported by AAS and EDX data. As expected, the brick sample originated from clay and sand due to the observed IR absorption peaks attributed to the minerals: hematite, calcite, illite, kaolinite, and quartz. Bricks are also found to be porous as observed from the SEM data which may be a good indication of its physical characteristics. The decomposition of minerals and carbonates in the brick sample below the firing temperature was analysed from TGA data. This may imply the presence of organic compounds that may have contaminated the sample through time.

\section{ACKNOWLEDGMENT}

The authors would like to express their sincere gratitude to the Municipality of Pagsanjan, Laguna, Pagsanjan Tourism, Culture and Arts Development Office, and most especially to Rev. Fr. Noel Artillaga, parish priest of Our Lady of Guadalupe for the old brick sample used in this study. The generous support of the Chemistry Department of the De La Salle University, Manila, is highly appreciated. This study is not possible without the helpful insights and assistance of the following persons from the 
De La Salle University, Manila: Dr. Glenn Alea, Mr. Michael Ajero, Mr. Irving Chiong, Dr. Maria Carmen Tan, Mr. Mamerto Quizon and Mr. Reynaldo Coria for the SEM-EDX data. The authors would also like to thank the invaluable assistance of Ms. Jessica Balingit from the Mapua Institute of Technology for running the TGA.

\section{DEDICATION}

To the Franciscan friars for building impressive church structures that forms part of our built cultural heritage and are worth protecting.

\section{REFERENCES}

Adams GI. Geologic reconnaissance of south western Luzon. Philipp J Sci. 1910; 5:57-113.

Alarcon N. Philippine architecture during the pre-Spanish and Spanish periods. UST Publishing House; 1998.

Cardiano P, Ioppolo S, De Stefano, Pettignano A, Serge S, Piraino P. Study and characterization of the ancient bricks of monastery of "San Filippo di Fragala" in Frazzano (Sicily). Anal Chim Acta. 2004; 519:103-111.

Cayme JM. Chemical characterization of historic brickworks made during the Spanish colonial period in the Philippines using scanning electron microscopy and energydispersive X-ray spectroscopy (SEM-EDX) and infrared spectroscopy (IR). $31^{\text {st }}$ Philippine Chemistry Congress; 2016 April 13-15; Iloilo City.

Cayme JM, Asor A, Jr. Extraction methods for quantifying iron, calcium and magnesium in a historic brickwork produced during the Spanish colonial period in the Philippines. Kimika 2015; 26(1):28-38.

Derrick MR, Stulik D, Landry JM. Infrared spectroscopy in conservation science: Scientific tools for conservation. The Getty Conservation Institute, Los Angeles; 1999.
Eslava-Faustino DV, Dimalanta CB, Yumul, Jr GP, Servando N, Cruz NA. Geohazards, tropical cyclones and disaster risk management in the Philippines: Adaptation in a changing climate regime. J Environ Sci Manag. 2013; 16(1):84-97.

Fernandes F, Lourenco P, Castro F. Ancient clay bricks: Manufacture and properties. In: Bostenaru Dan M, Poikryl R, Torok A. Materials, technologies and practice in historic heritage structures. Netherlands: Springer; 2010. p. 29-48.

Jose RT. Simbahan: Church art in colonial Philippines 1565-1898. Ayala Foundation Inc.; 1992

Kelly, J. Minerals in $\mathrm{KBr}$ pellets [internet]. Pasadena, California USA: Mineral Spectroscopy Server of the California Institute of Technology; 2011 [updated 2016 January 18; cited 2016 June 28]. Available from: http://minerals.gps.caltech.edu/files/Infrared _MIR/Minerals_From_JK/Index.htm

Klassen W. Architecture in the Philippines: Filipino building in a cross-cultural context (revised edition). University of San Carlos Press, Cebu City; 2010.

Mata RLS. The conservation of heritage conventos. Pintacasi, A Journal of the Cultural Heritage of the Church in the Philippines, 2005; 1:43-46.

Navarro M, editor. Common brick manufacture. 1st revised ed. Taguig City Metro Manila: Department of Science and Technology, Industrial Technology Development Institute; 2007 June.

Petrenas T, Kiuberis J, Opuchovic O, Tautkus S, Kareiva A. A closer look at the ancient bricks of historical monuments: essential step for the conservation of pottery. Chemija, 2012; 23(3): 194-202. 
Saikia BJ, Parthasarathy G. Fourier transform infrared spectroscopic characterization of koalinite from Assam and Meghalaya, North Eastern India. J. Mod. Phys., 2010; (1):206210.

Sathya P, Velraj G, Meyvel S. Fourier transform infrared spectroscopic study of ancient brick samples from Salavankuppam Region, Tamilnadu, India. Adv Appl Sci Res. 2012; 3(2):776-779.

Schumann W. Handbook of rocks, minerals and gemstones. Harper Collins Publishers and Houghton Mifflin Company, New York; 1993.

Schroeder PA. Infrared spectroscopy in clay science: In: Rule A, Guggenheim S, editors. CMS Workshop Lectures, Teaching clay science Volume 11. Aurora CO: The Clay Mineral Society; 2002. p. 181-206.

Smith WD. The geology of Luzon, P.I. J Geol. 1913; 21(1):29-61.
Soucek J, Holub FV, Jellnek E, Klapov AH. Calc-alkaline rocks. Encylcopedia of Earth Science. Springer US; 1989.

Sudo M, Listanco EL, Ishikawa N, Tagami T, Kamata H, Tatsumi Y. K-Ar dating of volcanic rocks from Macolod Corridor Southwestern Luzon, Philippines: Toward Understanding of the Quaternary Volcanism and Tectonics. J. Geol. Soc. Phil. 2000; 55:89104.

Sutcu M. Influence of expanded vermiculite on physical properties and thermal conductivity of clay bricks. Ceram Int. 2015; 41:2819-2827.

Torraca G. Lectures on materials science for architectural conservation. The Getty Conservation Institute, Los Angeles; 2009.

Zaide G. Pagsanjan in history and legend. Social Studies Publications, Inc.; 1975. 